ESENHA 


\section{PITA, MARÍA VICTORIA; PACECCA, MARÍA INÉS (ED.). Territorios de control policial: Gestión de ilegalismos en la Ciudad de Buenos Aires. Buenos Aires: Editorial de la Facultad de Filosofía y Letras Universidad de Buenos Aires, 2017. 300 p.; Colección Saberes.}

\section{Ana Paula Mendes de Miranda}

Professora do Departamento de Antropologia e do Programa de Pós-graduação em Antropologia da UFF; Bolsista de Produtividade do CNPq; Coordenadora dos Mestrados Profissionais de Antropologial Arqueologia da CAPES.

\section{CARTOGRAFIAS E HISTÓRIAS MÍNIMAS: ETNOGRAFIAS EXPERIMENTAIS SOBRE CONFLITOS URBANOS E A GESTÃO POLICIAL DE ILEGALISMOS}

A ideia de cartografar territórios como ferramenta de trabalho antropológico não é nova na Antropologia. No entanto, o que se passa no livro Territorios de control policial: Gestión de ilegalismos en la Ciudad de Buenos Aires é bastante distinto do que marcou os estudos dos anos 1950, voltados a espacializar as "áreas culturais", que resultou negativamente numa hierarquização de grupos sociais a partir da ideia centro-periferia ${ }^{1}$. O uso do conceito de território na construção de processos de identificações coletivas permaneceu relevante para superar a dicotomia entre espaço físico e espaço social.

O livro organizado por María Victoria Pita e María Inés Pacecca propõe pensar o território a partir de uma dimensão moral e política, e é sobre essa dimensão que o livro traz sua grande contribuição, porque ressalta a noção de soberania, que necessariamente se vincula à ideia de território. Estamos diante, portanto, da construção de "espaços", não de lugares, e dos modos de

Destacam-se os trabalhos de Clarck Wissler $(1917,1923,1926)$ e de Melville Herskovits (1955). O mérito desses trabalhos foi a construção de um método para organizar uma grande quantidade de dados etnográficos em unidades compreensíveis dentro de um sistema classificatório. O conceito de "áreas culturais" acabou sendo abandonado por mostrar pouco rendimento analítico (estático e limitado temporalmente). 
administração e regulação da violência, que pressupõe uma série de regras e acordos entre os atores. Essa discussão é aprofundada quando as autoras/ os autores optam por falar em territórios (no plural) para sublinhar a convivência e os antagonismos no contexto da cidade autônoma de Buenos Aires. Busca-se, assim, problematizar a tradição legal-política naturalista, segundo a qual a definição de território se constitui a partir de três elementos articulados: um agente (o Estado); uma ação (apropriação, controle, soberania, domínio, conquista por guerra); e uma superfície terrestre delimitada, para construir uma antropologia urbana que afirma o vínculo interativo entre relações sociais e o espaço construído. Estes fornecem exemplos de como as condições de disposição territorial - como possibilidade e como limite - revelam relações e estratégias de sobrevivência.

A história da configuração urbana de Buenos Aires, marcada por ciclos de atração para o centro e outros de ejeção centrífuga dos setores populares, caracteriza-se por um processo incremental de diferenciação socio-espacial, segmentação e segregação, por meio do qual a cidade foi estruturada em áreas cada vez mais homogêneas, de um lado, e mais heterogêneas de outro.

É nesse espaço social, político e moral que são apresentadas as formas de violência policial e os modos de administração de policiamento da população e/ou gestão da ordem pública. Orientado por um princípio igualitário de intervenção estatal, fica claro como são configuradas diversas situações violentas, a partir da intervenção do direito contravencional/direito policial - característicos de um direito administrativo - "la ley de la calle", que tece teias mais profundas que o direito penal.

O livro traz ainda outra contribuição metodológica muito relevante. Trata-se da opção por narrativas curtas, chamadas de "histórias mínimas", que revelam riqueza e complexidade do trabalho etnográfico em contextos de conflitos e violência estatal. Apresentam ao leitor os resultados de intensas observações, construídas a partir de situações de conversação e incursões, trabalho etnográfico exploratório, em vez de trabalhos a longo prazo, no sentido estrito do termo. Eles dão conta da singularidade de vários espaços de vida da cidade e fornecem uma escala intermediária que destaca os mapas narrados 
por pessoas que vivem diariamente naqueles territórios de controle policial. Trata-se de uma "etnografia experimental" que toma como referência as cenas que permitem evidenciar as mediações e conexões através das quais ocorrem os deslocamentos entre as fronteiras legais e ilegais. Segundo as editoras, o termo "histórias mínimas" foi escolhido por duas razões: a expressão que Foucault utilizava para fazer referência ao tipo de poder exercido pela polícia: um poder que é estendido para todo o corpo social - o poder político infinitamente pequeno (FOUCAULT, 2008). A outra motivação é o filme argentino de mesmo nome ${ }^{2}$, que consiste em uma série de histórias narradas por vários personagens que se cruzam sem perceber. Ao mesmo tempo, essas histórias se concentram nas "pequenas coisas" da vida, que no filme parecem ainda menores diante da imensa paisagem da Patagônia, onde o enredo se desenrola.

A leitura dessas histórias fez-me pensar em uma etnografia "intensa", para brincar um pouco com a ideia de uma etnografia densa, de Clifford Geertz (1989). Intensa pela forma como os casos são selecionados, a partir de um extenso trabalho de campo, permitindo tornar visíveis as formas pelas quais o poder da polícia é exercido em bairros pobres, bem como modalidades do exercício da violência, vigilância policial e controle (informal, ilegal e, às vezes, ilícito) sobre os jovens, configurando práticas violentas e diversificadas e arbitrariedades: ameaças, buscas, prisões por averiguação de identidade, "demoras" - detenção informal ou sem maior justificativa - e outras formas de assédio e maus-tratos.

A complexidade dessas situações revela uma porosidade acerca do que se costuma pensar no campo do direito como as fronteiras ${ }^{3}$ entre o legal e o ilegal. Esse cenário não implica necessariamente a existência de espaços sem regras, como por exemplo a ideia de que falta Estado (argumento presente no senso comum), ou de arbitrariedade e desregulamentação permanente. Ao contrário, revelam territórios sociais e morais de controle policial constituídos a partir de uma interseção entre legal e ilegal, gerando consequentemente diferentes relações de poder e domínio territorial.

\footnotetext{
2 Histórias mínimas (2002). O filme recebeu 11 prêmios nacionais e internacionais.

3 Ver Telles e Hirata (2007).
} 
Os capítulos desse livro apresentam sequências de fatos, intercâmbios e disputas entre atores desiguais, que, ao agir, têm seus atos traduzidos em "actas de infracción" pelas forças policiais, que têm o poder de lavrar. Ao fazê-lo, inscrevem as práticas suas e dos demais atores na construção de um território de controle policial.

A exploração das fontes midiáticas serve para demonstrar as teias dos conflitos e seus atores, no entanto, a abordagem privilegiada por essas agências é a de valorações negativas em torno da desordem, caos, ilegalidade, racismo e xenofobia.

O livro está dividido em duas partes, que se subdividem em capítulos, além dos textos de abertura. Mas há que se ressaltar que a obra não teve uma redação contínua - os textos foram redigidos por oito autores em diferentes momentos. A descontinuidade temporal da produção dos textos é bastante reveladora do que seja o trabalho etnográfico, resultante de uma pesquisa conduzida por um grupo de trabalho, apoiada por diferentes projetos institucionais, com diferentes perspectivas para entender as maneiras pelas quais a violência estatal se expressa sob a forma de disputas e resistências, acordos ou submissões e subordinações.

A obra é marcada por uma quantidade significativa de imagens (desenhos e fotos), que comunicam a seus modos próprios os tipos de trabalho desenvolvidos nas ruas. A maioria das fotografias - algumas em preto e branco, outras em cores - foram tiradas ao longo dos anos, enquanto a pesquisa durou (2008-2014), por fotógrafos profissionais que acompanharam a equipe durante o trabalho.

O uso da fotografia como uma tomada de posição - nem demasiado perto, nem demasiado longe - serviram para produzir um registro documental do cotidiano (como um dia de venda de rua, música no metrô, uma mobilização ou uma discussão na rua com policiais) para dar visibilidade ao mundo do trabalho e da ação coletiva, da vida urbana e também das violências e arbitrariedades. As imagens do livro não buscam recuperar a experiência vivida, mas apenas registrar alguns de seus momentos.

O carinho e cuidado que os textos, os mapas e as imagens revelam têm, para mim, sua melhor demonstração nos mapas bordados, que podem ser vistos 
nas páginas 240 a 244. Manufaturas de cor em trilhas de dor revelam caminhos e encruzilhadas compartilhadas durante anos. Pontos retos, cruzados e entrelaçados compõem as tramas dos bordados, tal qual as tramas das etnografias retratadas nesse livro.

Os autores e autoras fazem um jogo permanente de posições de câmera, conduzindo-nos a partir de uma visão aérea da cidade, levam a um zênite que permite diferenciar as áreas, os bairros e as avenidas em perspectiva humana. De uma grande escala se chega a zooms em cantos, barracas, panos. Ao revelar os detalhes, como instrumentos de trabalho, pertences, gestos ou bens, a câmera se move de fora para o interior dos corredores do Estado e faz foco em detalhes de arquivos, monitores de computador e tabelas estatísticas, como elementos que compõem a cidade e nos permitem entender como as burocracias que governam os territórios e os meios de comunicação que os representam atuam na construção da gestão de (i)legalidades.

O livro é, portanto, uma grande contribuição para a compreensão das formas específicas assumidas pela administração policial, no que se refere aos modos de governo de certas populações, e, ao fazê-lo, estabelece fronteiras fluidas entre legalidade, ilegalidade, legitimidade e arbitrariedade.

\section{REFERÊNCIAS}

1. FOUCAULT, Michel. Segurança, Território, População. São Paulo: Martins Fontes, 2008.

2. GEERTZ, C. A interpretação das culturas. Rio de Janeiro: Guanabara, 1989.

3. HERSKOVITS, Melville. Cultural Anthropology. New York: Random House, 1955.

4. HISTÓRIAS mínimas. Direção: Carlos Sorín. Buenos Aires: Martín Bardi, 2002. $94 \mathrm{~min}$.

5. TELLES, Vera S.; HIRATA, Daniel. Cidade e práticas urbanas: nas fronteiras incertas entre o ilegal, o informal e o ilícito. Estudos Avançados, São Paulo, v. 21, n. 61, p. $171-191,2007$. 
6. WISSLER, Clark. The American Indian: an introduction to the Anthropology of the New World. New York: Douglas C. McMurtrie, 1917.

7. WISSLER, Clark. Man and culture. New York: Thomas Y. Crowell, 1923.

8. WISSLER, Clark. The relation of nature to man in aboriginal America. New York: Ams, 1926. 